Blended E-Learning Skeleton of Conversation: improving formative assessment in undergraduate dissertation supervision

\title{
Aleksej Heinze and Beverley Heinze
}

Dr Aleksej Heinze is a lecturer in the Salford Business School, Universty of Salford, UK. His research interests are in blended e-learning, management education and search engine optimisation. Beverley Heinze is registered as an associate lecturer with the Open University, UK. Her research interests include innovative pedagogies, internationalization and management. Address for correspondence: $\mathrm{Dr}$ Aleksej Heinze, Salford Business School, University of Salford, Maxwell Building, 511b, Salford, Greater Manchester, UK. Tel: +44 (0)161 295 5024; fax: +44 (0)161 295 5999; email: a.heinze@salford.ac.uk

\begin{abstract}
The supervision of undergraduate student dissertations is an area in need of research. Although some studies have already addressed this, these are primarily based on academic staff responses.

This study contributes to knowledge by gathering the responses of students and focusing on formative electronic assessment. Data was collected using a student focus group and student questionnaire.

The findings suggest that good supervisor-student communication is crucial to the supervision process and a number of students felt unhappy with this aspect. It is suggested that to improve the undergraduate student dissertation experience, a combination of face-to-face and electronic formative assessment is used. In addition, the Blended E-learning Skeleton of Conversation model provides a sound theoretical framework that could guide supervisors and students in the supervision process. This model is advocated for use in dissertation module design and in supervisor development.
\end{abstract}

\section{Introduction}

Higher Education Institutions (HEIs) are increasingly placing emphasis on widening participation and equality and diversity (Doyle and Robson, 2002). Internationalisation is also gaining importance. Worldwide, it is estimated that about 2 million students are studying outside their home country and this figure is projected to increase to 8 million by 2025 (Altbach, 2004). Both, widening participation and international students can benefit from the use of information communication technologies where feedback, if written electronically, can be read at a later stage, where necessary using assistive technologies. This potentially allows students to understand and better engage with the learning process. Arguably, this is true of all students - international or home although it is recognised that supervising international students:

"may require more time, effort and skill that supervising home British students" (McNamara and Harris, 1997:140).

This creates a tension in higher education, where the supervision of international students demands a certain level of altruism on the part of the lecturer. This is not currently accounted for in UK higher education and some lecturers might be tempted not to put the effort into such activities (Edwards, 2006).

The move towards social constructivist pedagogies in post-compulsive education (Cullen et al., 2002), suggests that one of the important indicators of good education is 'feedback' - which is recognised as a crucial element of the student learning process (Heinze, Procter, and Scott, 2007). Feedback is a major part of the formative assessment process which aims to inform both students and lecturing staff about the learning progress of students (QAA, 2006). 
The literature on undergraduate dissertation supervision is limited and is dominated by the opinions of lecturing staff (M. J. Todd, Smith, and Bannister, 2006). Therefore, there is the need for a study that explores the views of students. Moreover, this study examines the pedagogic format of formative assessment and the communication process between the supervisor and student.

The main sections of this paper are as follows: an examination of the relevant literature, a description of the data collection and finally a discussion and conclusions.

\section{Communication and feedback}

An undergraduate dissertation allows the student to undertake a substantial piece of independent work. The associated freedom has the negative effect of 'chaos' and 'cosmos' where students feel uneasy and yet excited about their dissertation journey (Sile'n, 2003). This requires the supervisor to step in and guide the student in their move towards becoming a self-directed learner (M. Todd, Bannister, and Clegg, 2004). However, supervisors can themselves find supervision challenging and are also likely to experience elements of 'chaos' and 'cosmos' (M. J. Todd et al., 2006). This challenge is compounded by the increasing numbers of international and widening participation students, who may require more intensive and time consuming attention. A common way of dealing with this is for the supervisors to develop risk management skills (McWilliam, Singh, and Taylor, 2002). Research skills, time management and communication skills are highlighted by others as being crucial and in particular, the need for clear dissertation supervision guidelines (McMichael, 1993). Some basic supervision guidelines are as follows:

"encourage students to make good use of the supervision process', 'manage and structure the process for the student' and 'expect the student will have difficulties with the literature review” (Rowley, 2000:14).

There is divided opinion about who should be managing the supervision process. For example, the participants of the Todd, Smith et al (2006) study agreed that the role of the student in the undergraduate dissertation process is as the driver. The student should develop time management and organisational skills, in other words, they must take ownership of problems and manage meetings with supervisors and then steer the content of those meetings.

Additionally, the supervisory role changes as the supervision process progressed. At the beginning of the first semester the supervisors were more authoritative and prescriptive in their guidance. However, as the student progressed, the supervisors tended to adopt more of a 'hands off' approach, creating a tension between too much guidance and too little (M. J. Todd et al., 2006).

When it came to the provision of feedback, it was generally agreed by the Todd et al (2006) study, that feedback to the students was only given at draft stages and not on the finished work. Feedback on the development of research questions and the use of research methods was commonly accepted as pertinent. Additionally, several participants said that they were willing to highlight technical issues such as grammar, referencing methods and spelling mistakes (M. J. Todd et al., 2006). At the same time we are aware of the studies surrounding formative feedback which argues that frequent formative feedback is an important element when it comes to achieving substantial learning gains (Black and William, 1998). Whilst tools such as Multiple Choice Questions (MCQs) are applicable to more generic modules and subjects (Nicol, 2007), they are not applicable to the use on dissertations where each subject differs and the formative feedback relies heavily on the individuals: the student and the supervisor.

\section{Pedagogy}

Social constructivists recognise the individuality of learners and the need to be aware of their social nature. Thus, individuals are at the centre of the learning process and teachers facilitate their learning, 
hence the term 'facilitator' is preferred to 'teacher'. Therefore, the role of the staff involved in the supervision is a critical success factor to students’ success (Heinze and Procter, 2008).

Gordon Pask (1928 -1996) and others advanced the constructivist paradigm in the 1970's through Conversation Theory (Scott, 2001b). The central idea of a dialogue, which is advanced by the Conversation Theory and represented by the Skeleton of Conversation, was further developed by the Conversational Framework (Laurillard, 1993). Although widely cited, the Conversational Framework is not widely used in practice (Dyke, Conole et al 2007), for a number of reasons, including a lack of practical considerations and most importantly its implicit reference to assessment (Heinze, Procter et al 2007). As a result of deficiencies in accommodating assessment and the increasing need to integrate face-to-face sessions with e-learning tools, the Blended E-Learning Skeleton of Conversation was developed (Heinze et al., 2007). One of the key improvements advocated by the Blended E-Learning Skeleton of Conversation is that it makes the role of Assessment explicit in the model and breaks the assessment process into three stages: a) Learning how to learn, b) Learning the topic and c) Applying the topic. The developments in the e-learning domain offer and ever increasing range of e-assessment tools as highlighted in the JISC report (Whitelock and Brasher, 2006) and other studies that explore this issue based on the UK Open University, which is at the forefront of developments in this area (Whitelock, 2006).

A representation (see Figure 1: Blended E-Learning Skeleton of Conversation) outlines the three stages highlighted by the Skeleton of Conversation (the additions to the original Conversation Theory representation are italicised and a grey background is used). As in the original model, the horizontal arrows illustrate the dialogue between the teacher and the learner. These are constructed on at least two logical levels - addressing the 'how' and the 'why' questions (Scott, 2001a). The 'how' level questions are focusing on how to engage with a topic, for example in the case of a dissertation - how to write a dissertation? The 'why' level questions are focused on justifying and explaining a topic in terms of its meaning in the context of other topics, for example - why a dissertation has a certain structure? The vertical arrows of the model illustrate the development of causal elements of learning, where both the teacher and the learner are developing their understanding of the situation. For example the learner, having understood why and how they need to engage with the learning of the dissertation, can now better understand the why and how of the topic that they are to study as part of the dissertation.

The initial stage of communication is represented by the top left quadrant, which signifies the teacher's explanation in terms of the learning process. This addresses the 'why' and 'how' questions and responses, allowing students to engage with Learning how to learn. For example, in relation to the undergraduate dissertation process, at this stage the student would be informed of the reasons for undertaking the dissertation and how the process works. At the end of this interaction, a student is asked to produce a piece of work for summative assessment. An example of such work could be a dissertation proposal. Whilst the actual process of 'dissertation proposal preparation' assumes that students would meet with the supervisor on a regular basis and hence facilitate formative feedback, this model allows us to manage those situations where either the student or the supervisor do not engage in the formative feedback processes. However, in the ideal situation, the small weighting and a deadline of a proposal submission will focus both the supervisor and the student in engaging in the feedback process. Therefore, the Blended E-Learning Skeleton of Conversation brings with it the 'real life' problems of what is essentially a team effort (student and supervisor) and facilitates their discussion by imposing an external deadline of summative assessment. This provides a minimum interaction level between the student and the supervisor. This also addresses the limitation of the Conversational Framework, which assumes that students are interested in engaging in dialogue to receive formative feedback (Heinze et al., 2007). Furthermore, the Blended E-Learning Skeleton of Conversation allows peer learning, but in the case of a dissertation process, unless the supervisor has a group of students to supervise, this cannot be undertaken. This is not to say that informal learning does not occur. 
The second stage of communication, Learning the topic, illustrated by the Blended E-Learning Skeleton of Conversation is concerned with the 'why' and 'how' of the subject being studied, and is represented by the first paragraph at the bottom left quadrant in figure 1. At this stage, the roles of the student and the teacher become reversed - as the student becomes more in-charge of the topic, and the relevant justification for why it will be studied and how they propose to approach it. This stage of the supervision is advanced by summative assessment, which could be take the form of an interim report.

[FIGURE 1 - ideal position here]

The third and final stage of the supervision process, Applying the topic, would be to prepare a learner for the final submission of their dissertation. This could in some subjects that are more practice based, result in the production of artefacts, models or simply the written dissertation document.

This model is in line with Constructive Alignment, as advocated by Biggs (1999), which suggests that each curriculum objective should be aligned with assessment. In the Blended E-Learning Skeleton of Conversation, Constructive Alignment is symbolised by the horizontal arrows that lead from the teacher towards the learner and backwards via discussion and summative assessment.

\section{Description of data collection tools}

Given the sensitive nature of this work with students who are still being taught and assessed, ethical approval was sought at every stage of data collection. The student respondents were re-assured that their contributions were voluntary and did not impact on their assessment. The dissertation module coordinator was informed of this work and she consented and collaborated where possible to help with data collection.

Study context

This research was undertaken in the Salford Business School, University of Salford, UK. The final year students involved in this study are from three full time programmes: BSc (Hons) Business Information Systems; BSc (Hons) Business Information Technology; BSc (Hons) eCommerce Systems and one part-time programme in BSc (Hons) Information Technology. Whilst the requirements vary slightly for the part time and the full time students in the way that the former also have to present their work orally for assessment, the three other deliverables of proposal, interim report and the final report are identical and for the purposes of simplicity these will not be differentiated in the current study. Overall, at the time of study there were 35 part-time and 50 full-time students registered on the dissertation module. There were 15 supervisors who supervised all the students

The dissertation supervision process in the given study spans an academic year (September to May). The Blended E-Learning Skeleton of Conversation is mapped against the assessment stages: The three assessments that students are expected to submit are spread out so that a proposal is due approximately one month after they begin their work and accounts for $5 \%$ - Learning how to learn; the interim report is due in the mid-semester break and accounts for $10 \%$ - Learning the topic; and the final work accounts for the remaining $85 \%$ - Applying the topic. All final submissions are to be made in hard copy.

\section{Data collection processes}

A focus group session was facilitated to elicit the views of students on the programme about the dissertation module and this took place near the end of the module. All students were emailed and invited to attend the session, the sample of 5 students was therefore self-selected. The students were motivated to attend by being offered refreshments. Two external individuals, whom the students did not know, facilitated the focus group and produced a report that was emailed to the students to confirm validity and comments. During the focus group session the students were asked to comment on their positive and negative experiences during the dissertation module. Given the exploratory nature of the focus group, the students dictated the topics that they could discuss. 
Building on the findings of the focus group, which highlighted issues in the dissertation supervision process, a nine question online survey was devised. This survey was open to students the week after they submitted their dissertations. Overall, 35 of the 85 students (approximately 41\%) replied to the survey. To differentiate between the respondents each of them is identified by a unique number from 1 to 35 that were assigned automatically by the online survey tool.

\section{Discussion}

The data from the student focus group indicated that there were positive instances where the supervisors were approachable and available for consultations and meetings and provided influence on the dissertation planning. However, there were other instances where this was not the case. One of the main areas for improvement identified by the students in the focus group was that in some cases they felt that there was a lack of communication between the student and the supervisor:

"... the major problem with dissertations was the lack of communication with the supervisor. In some cases the supervisor was not available, was unhelpful and held infrequent meetings..." Student focus group

This highlights the learning problem as identified in the Blended E-Learning Skeleton of Conversation at all three stages, which requires both the student and supervisor to take part in a dialogue. Where dialogue does not take place due to communication issues, there is a negative impact on the learning process of the student.

The students were aware that the dissertation was an independent piece of work and that the role of the supervisor was to provide general guidance and help with the dissertation journey. There were mixed responses regarding the reality of the supervision process, and the students noted that its success depended largely on the individual supervisor that they were allocated, highlighting inconsistencies in the supervision process:

"A positive experience of completing a dissertation very much depended who you had as supervisor. In some cases the supervision was good while in other instances there was a bad experience. The course needs to show consistency throughout." Student focus group

A view presented by Todd, Smith et al (2006), which focused on the responses of academic staff, places the emphasis of the supervision on the student - it is their skills that are supposed to be developed after all. However, on asking students in this study we realise that they have a contrary view, despite the acknowledgement of the need for their own development. The students felt that the supervisor should take a more pro-active role, supporting the view of Rowley (2000).

There was a lack of consistent supervision processes on the programme, supporting the literature that claims that the individuality of staff is the main variable in determining the student learning experience (Heinze and Procter, 2008). The tensions in the given study are also in line with the literature that gives contradicting views on what the supervisor's role should be. It could be that of managing the students (Rowley, 2000), or that of giving the students the opportunity to manage themselves (M. J. Todd et al., 2006). However, this suggests the need for supervisor and student guidelines, which could be used to negotiate expectations. However, as in the literature, supervisors in the given study do not appear to be in agreement. Currently, there are no minimum contact times prescribed in the dissertation handbook apart from the suggested 30 minutes per fortnight: 
"The frequency and length of the meetings will depend on the stage of the project and the agreement between student and supervisor; as a guideline the student is entitled to expect the supervisor to be available for half an hour per fortnight"(Kutar, 2007:5)

This guideline appears reasonable and is similar to that suggested by (M. J. Todd et al., 2006) where it is stated that the time of the dissertation meetings also influenced the level of support provided. The students stated that there were some supervisors who were very inflexible with their meeting times, unhelpful in meetings and held the meetings infrequently. This raises the question - how frequently should a student see and communicate with their supervisor and is it possible to generalise? This issue was one of the main drivers for the design and creation of the survey.

\section{Survey findings}

The survey aimed to explore the concerns raised in the focus group: namely, both the communication channels used by the students and their supervisors and the feedback provision. The nine questions will be briefly discussed in turn. It should be noted that due to the limited size of the survey, the claims made are not statistically significant and therefore only trends are of interest in this respect, therefore the percentages are rounded up to illustrate approximate numbers.

When asked about the frequency of face-to-face meetings students held with their supervisors, the minority response of $30 \%$ (eight students) was: once every fortnight and once a week - which is in line with the module handbook. The remaining students have either never seen their supervisor $6 \%$ (2 students) or have seen them less frequently than once a fortnight. This supports the feelings of those students in the focus group, who said that the way that supervision took place was mixed and depended on individuals. Also, this could imply that face-to-face communication was substituted by other media.

The overwhelming majority of $82 \%$ (27 students) stated that they never telephoned their supervisor. However, there was a feeling that some students did not wish to encounter a delay as when communicating over email and that there were situations when a telephone conversation could have been preferable:

"14. Some supervisors only allow email contact, whereas phone contact is a good solution for those students who have a quick question. Also, some supervisors have other priorities which are more important than dissertations...."

This again highlights the limitations of the Conversational Framework, which assumes that the supervisor is interested in engaging with the student and adds another dimension to the 'dialogue engagement' problem, which in previous studies was highlighted from the students' perspective. To have dialogue there is a need for two parties and if either of the two is not taking part the dialogue is not present, reducing the likelihood of formative feedback being given and received. To manage such problems an externally imposed process of summative can be beneficial.

Yet, the frequency of email communication indicated that the majority 52\% (17 students) had contact with their supervisor at least every fortnight. This indicates that there was more frequent interaction with students via email than during face-to-face meetings. This observation could be explained by the nature of the programmes studied, but it could also be a trend indicating that there is some comfort for students and supervisors in the consistency and ongoing relationship of communicating via email. This strengthens the trend observed in HEIs that technology facilitated communication is becoming more common. Therefore, Blended Learning is a reality for which a pedagogic foundation is required and in this case the Blended E-Learning Skeleton of Conversation offers a good guide. This pedagogically developed principle, based on a teacher-student dialogue and motivated by assessment provides a structure for a conversation and allows flexibility when using different media. The choice of media for communication can be agreed upon by both the dissertation supervisor and the student. 
The three main iterations offered in the Blended E-Learning Skeleton of Conversation also point to at least three feedback loops between the student and the dissertation supervisor. These three fit perfectly with the model adopted on the studied dissertation module where a proposal - addressing the Why and How questions of learning; interim report - addressing How and Why questions of the subject; and the dissertation - addressing the demonstration of the final document.

The ideal in terms of frequency of contact with a supervisor, was felt by 65\% (or 22 students), as being once every week or every two weeks. Interestingly, no responses stated that there was no need to contact the supervisor at all. However, there was one student, who felt that contacting their supervisor only once was sufficient, this is clearly against the main trend.

The question that asked students for their views about how the supervision process could be improved revealed several comments about the speed and frequency of communication as well as the organisation of meetings:

“6.Guaranteed same/next day reply via telephone, e-mail, text.”

When asked about their preferred format of feedback received, the majority selected verbal feedback, closely followed by written notes, then comments on electronic files and tracked changes. However, what the students found most useful was a combination of several methods with verbal and written being some of the most frequent options chosen. This finding is in line with the literature on the supervision of international and widening participation students, and suggests that the use of electronic comments and feedback does provide all students with a better opportunity to engage with the learning process and benefit from electronic communication with their supervisor. However, it is noted that the students still feel that face-to-face communication is necessary.

The student views on improvements to supervisor feedback varied. The majority of suggestions were similar to those concerning communication - the speed and frequency of feedback could be increased. Some also mentioned the use of different technologies such as common discussion forums, instant messaging and facebook:

"20. Well it can improved by supervisors having a discussion forum for their students so that every one can share their views and exchange information if really needed"

“26. Maybe via instant messenger or facebook”

Suggestions to introduce a social aspect and potentially allow several students to share their questions and answers is in line with the Blended E-Learning Skeleton of Conversation, which recognises social learning and encourages student-student interaction when learning.

\section{Conclusions}

In conclusion, all the evidence gathered points to one key variable that is the 'people' or 'individuals' involved in the process. For example, one supervisor can and sometimes has to adopt different supervision tactics based on both the performance of individual students and their progress on the dissertation journey. Students expressed varied opinions, with some wanting to be closely supervised and others to be more independent. However, there was evidence in both the student focus group and the survey to suggest that students wanted more supervision - the majority preferred to have more communication and feedback from their supervisors and once or twice a week was the preferred frequency. 
The pedagogic literature supports the need for communication between the learner and the supervisor. The Blended E-Learning Skeleton of Conversation highlights the need for at least three main feedback cycles between the supervisor and the student. The use of technologies in facilitating this interaction is becoming more varied, with students suggesting the use of electronic comments, track changes, social discussion forums, instant messaging technologies and social networking sites such as Facebook. This poses a challenge and also an enabler to the supervision relationship. Having the feedback in electronic format also helps international and widening participation students.

The findings of this paper are aimed at supervisors who are exploring their own practice and are seeking ways to improve their process of supervision. Therefore, the model suggested in this work can be used as a reflection framework on the dissertation process and is grounded in constructivist pedagogic believes. The model questions the basics of the constructivist dialogue highlighting the potential lack of student and supervisor engagement in the formative feedback processes. Also, as advocated by (Shepard, 2000) this model integrates assessment as part of the learning process and not as an end of learning check point. Hence the contribution on this paper is to the literature on curriculum design as well as to the staff development domains. The new insight generated by the findings is based on the student voice and the students' interpretations of their undergraduate dissertation supervision, which was lacking in the literature. Further larger scale studies are encouraged to compare the findings across institutions and across disciplines.

Due to the size of the focus group and the survey responses, this study has highlighted indicative trends which could benefit from future research on a larger scale. Despite these limitations, this work echoes some of the issues raised in the literature and highlights the need for electronically facilitated feedback communication.

\section{Acknowledgements}

We would like to acknowledge the time and support given by the focus group facilitators: John Owen and Clive Yates and feedback and constructive discussions with Dr Viv Caruana. Most importantly we would also like to thank all students who participated in the focus group and the online survey.

\section{References:}

Altbach, P. G. (2004). Higher Education Crosses Borders. Change, Retrieved from: www.bc.edu/bc_org/avp/soe/cihe/publications/pub_pdf/Student\%20_flows.pdf.

Black, P., \& William, D. (1998). Assessment and classroom learning. Assessment in Education, 5(1), 7-74.

Cullen, J., Hadjivassiliou, K., Hamilton, E., Kelleher, J., Sommerlad, E., \& Stern, E. (2002). Review of current pedagogic research and practice in the fields of post-compulsory education and lifelong learning (Report). London: The Tavistock Instituteo. Document Number)

Doyle, C., \& Robson, K. (2002). Accessible Curricula: Good Practice For All. Cardiff: University of Wales Institute (UWIC) Press.

Edwards, V. (2006). Meeting the needs of Chinese students in British Higher Education. Reading: The University of Readingo. Document Number)

Heinze, A., \& Procter, C. (2008). Is Blended Learning a 'silver bullet' for part-time mature student education? Paper presented at the Blended Learning Conference 2008. from http://www.herts.ac.uk/fms/documents/teaching-and-learning/blu/conference2008/AleksejHeinze-2008.pdf

Heinze, A., Procter, C., \& Scott, B. (2007). Use of Conversation Theory to underpin Blended Learning. International Journal of Teaching and Case Studies, $1(1 \& 2), 108-120$.

Kutar, M. (2007). UG Dissertation Handbook. Salford: University of Salfordo. Document Number)

Laurillard, D. (1993). Rethinking university teaching: A framework for the effective use of educational technology. London: Routledge/Falmer.

McMichael, P. (1993). Starting up as supervisors: the perceptions of newcomers in postgraduate supervision in Australia and Sri Lanka. Studies in Higher Education, 18(15), 15-26.

McNamara, D., \& Harris, R. (1997). Overseas Students in Higher Education: Issues in Teaching and Learning. London: Routledge. 
McWilliam, E., Singh, P., \& Taylor, P. G. (2002). Doctoral education, danger and risk management,. Higher Education Research \& Development, 21, 119 - 129.

Nicol, D. (2007). Laying a foundation for lifelong learning: Case studies of e-assessment in large 1styear classes. British Journal of Educational Technology, 38(4), 668-678.

QAA. (2006). Code of practice for the assurance of academic quality and standards in higher education Section 6: Assessment of students - September 2006 o. Document Number)

Rowley, J. (2000). Thirteen tips for successful supervision of undergraduate dissertations,. Staff and Educational Development Association, 1(14), 14-15.

Scott, B. (2001a). Conversation Theory: A Constructivist, Dialogical Approach to Educational Technology. Cybernetics and Human Knowing, 8(4), 25 - 46.

Scott, B. (2001b). Gordon Pask’s Conversation Theory: A Domain Independent Constructivist Model of Human Knowing. Foundations of Science, special issue on "The Impact of Radical Constructivism on Science", 6(4), 343 - 360.

Shepard, L. A. (2000). The Role of Assessment in a Learning Culture. Educational Researcher, 29(7), 4-14.

Sile'n, C. (2003). Responsibility and independence: what is the role of the educators and the framework of the educational programme? Paper presented at the 11th Improving Student Learning Conference, Hinckley, UK.

Todd, M., Bannister, P., \& Clegg, S. (2004). Independent inquiry and the undergraduate dissertation: perceptions and experiences of final-year social science students. Assessment \& Evaluation in Higher Education, 29(3), 335-355.

Todd, M. J., Smith, K., \& Bannister, P. (2006). Supervising a social science undergraduate dissertation: staff experiences and perceptions. Teaching in Higher Education, 11(2), 161 - 173.

Whitelock, D. (2006). Electronic Assessment: Marking, Monitoring and Mediating Learning. Interactions, Objects and Outcomes in learning. Special Issue of International Journal of Learning Technology, 2(2/3), 264 - 276.

Whitelock, D., \& Brasher, A. (2006). Roadmap for e-assessment. Bristol JISC 
Blended E-Learning Skeleton of Conversation

Teacher

Learner(s)

Summative Assessment

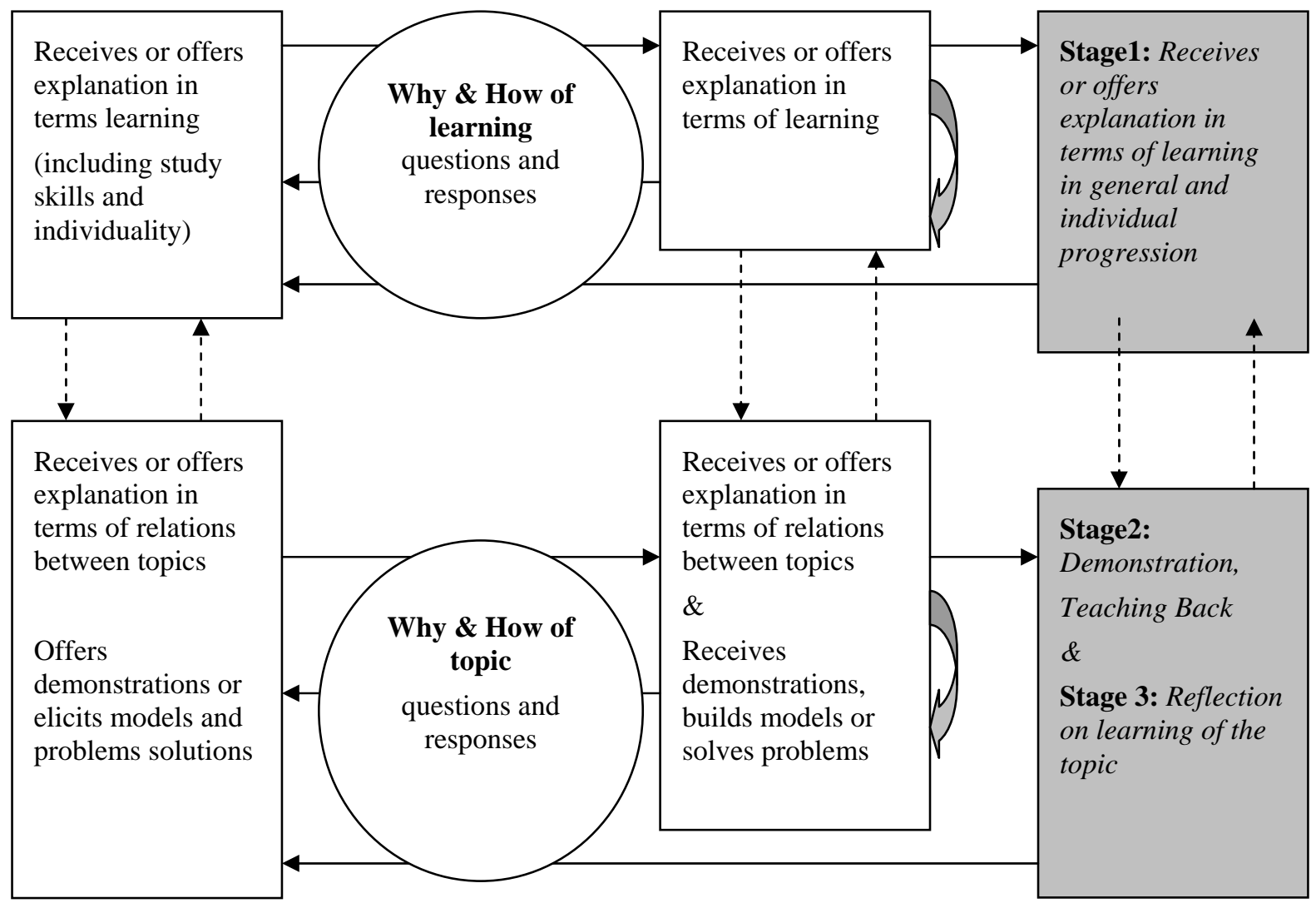

Figure 1: Blended E-Learning Skeleton of Conversation 